\title{
A Method for Multi-attribute Decision Making Under Uncertainty Using Evidential Reasoning and Prospect Theory
}

\author{
Liuqian Jin $^{1,2}$, Xin Fang ${ }^{3}$, Yang $\mathrm{Xu}^{2}$ \\ ${ }^{1}$ School of Economics and Management, Southwest Jiaotong University, \\ NO.111 of the North Second Ring Road, \\ Chengdu, Sichuan province 610031, P.R.China \\ E-mail: jinliuqian@163.com \\ ${ }^{2}$ System Credibility Automatic Verification Engineering Lab of Sichuan ProvinceSouthwest Jiaotong \\ University, \\ NO.111 of the North Second Ring Road, \\ Chengdu, Sichuan province 610031, P.R.China \\ E-mail: xuyang@home.swjtu.edu.cn \\ ${ }^{3}$ School of Transportation and Logistics, Southwest Jiaotong University, \\ NO.111 of the North Second Ring Road, \\ Chengdu, Sichuan province 610031, P.R.China \\ E-mail:qbo10086@163.com
}

Received 7 February 2015

Accepted 27 October 2015

\begin{abstract}
In this paper, a method for multi-attribute decision making under uncertainty is proposed, the uncertainty is represented by certitude structure. In fact, there are both quantitative and qualitative attributes with different representation in multi-attribute decision making under uncertainty, so the certitude structure transformation method is the first contribution of this paper. Secondly, the prospect value vector for each alternative on each attribute is calculated based on prospect theory. Thirdly, the combination decision prospect value of each alternative is given according to evidential reasoning approach under certitude degree. Then a ranking of alternatives can be determined using the combination decision prospect values. Finally, two illustration examples are used to illustrate the use of this multi-attribute decision making method, as well as demonstrate its high performance by comparing with the existing approaches.
\end{abstract}

Keywords: multi-attribute decision making; certitude degree; evidential reasoning; prospect theory

\section{Introduction}

In the objective physical world, there are many Multi-Attribute Decision Making (MADM) problems involve both quantitative and qualitative attributes with various kinds of uncertainties. These uncertainties are associated with the subjective humans mental activities such as randomness ${ }^{1}$, fuzziness ${ }^{2}$, indetermination ${ }^{3}$, indistinguishability ${ }^{4}$, incomparability ${ }^{5}$, incompleteness ${ }^{6}$, incredibility, ignorance and so on ${ }^{7}$. In many circumstances, the attributes, especially qualitative ones, could only be 
properly assessed using human judgment which is subjective in nature and is inevitably associated with uncertainties. Even some attributes or phenomena with owned uncertainties.

There is an extensive literature about MultiAttribute Decision Making under Uncertainty (UMADM) method. Montes et al. ${ }^{8-11}$ focus mostly on two different optimality criteria that serve as an alternative to the expected utility model: stochastic dominance and statistical preference, and make decision by considering all the probability measures and utility functions compatible with the available information. Park et al. ${ }^{12}$ thought that risk is caused by the uncertainty of nature state and a decision makers action and proposed an expected utility and uncertainty risk model by making a compromise between measures of expected utility and uncertainty. $\mathrm{Fu}$ and Yang ${ }^{13}$ developed an evidential reasoning based consensus model to find commonly satisfactory solutions to multi-attribute group decision making problems with interval belief structures. Guo et al. ${ }^{14}$ gave several pairs of preference programming based on evidential reasoning algorithm with interval uncertainty, defined and computed the maximum and minimum expected utilities for each alternative.

Expected Utility Theory (EUT) ${ }^{15}$ served for this purpose for a long time as a normative model of rational choice. However, actual choices often exhibit systematically deviations from this widely accepted theory. This discrepancy has given impetus to competing theory that attempt to explain individual behavior under conditions of uncertainty, an alternative model, Prospect Theory (PT) was developed by Nobel economics laureate Kahneman and Tversky ${ }^{16}$. The purpose of this descriptive model is to explain agents behavior in uncertain environments, which remained unexplained by EUT ${ }^{17}$.

Kahneman and Tversky ${ }^{16}$ discovered judgment and decision of actual decision making behavior deviating from the EUT under uncertainty through the experiments, and the PT was proposed, which is the first-generation prospect theory. The value function and weight function instead of the utility function in EUT are used to describe decision making behavior. The outcomes are expressed by means of gains and losses from a reference alternative. PT is an important research achievement on behavioral economics, and it has successfully been used as behavioral model of decision making under risk mainly in market decision making ${ }^{18}$, economics ${ }^{19-20}$, finance ${ }^{21}$, risk management ${ }^{22}$, etc. Due to the firstgeneration prospect theory is the conceptual model, Tversky and Kahneman ${ }^{23}$ developed the Cumulative Prospect Theory (CPT or PT for short) in 1992. CPT capture psychological aspects of decision making under risk using value function, weight function and weighted sum method.

Generalized decision theory include two types: prescriptive decision theory and descriptive decision theory. Prescriptive decision theory researches how to make decision in theoretically research, descriptive decision theory researches how to make decision through the empirical research. Behavioral scientists, social scientists and philosophers try to find more detailed descriptive model of decision making process which in order to provide more advanced prescriptive decision making process for mathematician, economist, business management and other personnel. In this paper, we research a prescriptive decision making method based on the behavioral scientists research achievement-Prospect Theory (PT) and uncertainty inference method-Evidential Reasoning (ER) to support decision making.

In a real world decision situation, decision maker often faces classification or integration of uncertainty information, uncertainty reasoning and decision judgments. The ER approach ${ }^{24-29}$ is an effective information fusion and uncertainty reasoning method for decision making ${ }^{30}$. And the ER approach provides a novel procedure for aggregating multiple attributes based on the distributed assessment and the evidence combination rule of the Dempster-Shafer theory. Within this ER assessment framework, there are some characteristics need to notice:

(i) uncertainty structures are represented as belief structure;

(ii) the belief structures of different attributes with the same evaluation grades;

(iii) for decision making, suppose that there are different utility of the each grades, then calculate 
the maximum expected utilities, minimum expected utilities and average ones.

Influenced by these first two characteristics, belief structure cannot be a pretty good description of uncertainty. Therefore, we will make decision using certitude degrees directly in this paper. For the third characteristic, the utility of each grade only need to be meet that the greater grade with more utility without specific method. Therefore, we will make decision using value function and weight function of PT in this paper. In general, the certitude degree is the representation of uncertainty, PT is the descriptive decision making method and ER approach under certitude degree ${ }^{31}$ is the inference method. In this case, the prescriptive decision making method is proposed and the alternatives can be select by combination decision prospect value.

In this paper, we develop a decision making method based on the PT and ER for solving the UMADM problems. The rest of this paper is organized as follows. Section 2 is the preliminaries, including normalization methods, certitude structure transformation methods and certitude rule based inference method. The representation of MultiAttribute Decision Making with Certitude Degree (MADM-CD) problem is proposed, and the MultiAttribute Decision Making method using Prospect Theory and Evidential Reasoning (PT-ER method) is also developed in Section 3. In Section 4, two illustration examples are given for PT-ER method, and compared with some existing approaches. Conclusion are drawn in Section 5.

\section{Preliminaries}

\subsection{Normalization methods}

The well known normalization methods include range normalization method, max/min linear normalization method, sum normalization method and vector normalization method ${ }^{32-33}$. These normalization methods are based on the linear variation hypothesis, but in fact, different attributes from different sides reflect the different characteristics of things, the characteristics are often nonlinear. In order to describe the change law of the normalized at- tribute values more accurately, according to the diminishing marginal utility law in microeconomics, the range-logarithm normalization method, logarithm normalization method and max/min-logarithm normalization method are given.

Suppose that $y_{i j}(i=1,2, \cdots, I ; j=1,2, \cdots, J)$ should be normalized and $Y=\left[y_{i j}\right]_{I \times J}$, the normalized value is $z_{i j}$ for each $y_{i j}$. There are three normalization methods are given as follows.

(i) range-logarithm normalization method

(a) benefit type

$$
z_{i j}=\log _{2}\left(\frac{y_{i j}-\min \left\{y_{j}\right\}}{\max \left\{y_{j}\right\}-\min \left\{y_{j}\right\}}+1\right)
$$

(b) cost type

$$
z_{i j}=\log _{2}\left(\frac{\max \left\{y_{j}\right\}-y_{i j}}{\max \left\{y_{j}\right\}-\min \left\{y_{j}\right\}}+1\right)
$$

where $\min \left\{y_{j}\right\}=\min \left\{y_{1 j}, y_{2 j}, \cdots, y_{I j}\right\}$, $\max \left\{y_{j}\right\}=\max \left\{y_{1 j}, y_{2 j}, \cdots, y_{I j}\right\}$, $\max \left\{y_{j}\right\} \neq \min \left\{y_{j}\right\}$. The normalization attribute values have the same metric space, the maximum value is 1 , the minimum value is 0 . This normalization method is not suitable for the attribute of which the maximum and minimum values are both the same number.

(ii) logarithm normalization method

(a) benefit type

$$
z_{i j}=\frac{\ln \left(y_{i j} / \min \left\{y_{j}\right\}\right)}{\ln \left(\max \left\{y_{j}\right\} / \min \left\{y_{j}\right\}\right)}
$$

(b) cost type

$$
z_{i j}=\frac{\ln \left(\max \left\{y_{j}\right\} / y_{i j}\right)}{\ln \left(\max \left\{y_{j}\right\} / \min \left\{y_{j}\right\}\right)}
$$

where $\min \left\{y_{j}\right\}=\min \left\{y_{1 j}, y_{2 j}, \cdots, y_{I j}\right\}$, $\max \left\{y_{j}\right\}=\max \left\{y_{1 j}, y_{2 j}, \cdots, y_{I j}\right\}, y_{i j} \neq$ $0(i=1,2, \cdots, I)$. The normalization attribute values have the same metric space, the maximum value is 1 , the minimum 
value is 0 . If the attribute value is 0 , then this attribute value do not participate the minimum operation and maximum operation. The normalization value of attribute value 0 is 0 .

(iii) $\max /$ min-logarithm normalization method

(a) benefit type

$$
z_{i j}=\log _{2}\left(\frac{y_{i j}}{\max \left\{y_{j}\right\}}+1\right)
$$

(b) cost type

$$
z_{i j}=\log _{2}\left(\frac{\min \left\{y_{j}\right\}}{y_{i j}}+1\right)
$$

where $\min \left\{y_{j}\right\}=\min \left\{y_{1 j}, y_{2 j}, \cdots, y_{I j}\right\}$, $\max \left\{y_{j}\right\}=\max \left\{y_{1 j}, y_{2 j}, \cdots, y_{I j}\right\}$, $\max \left\{y_{j}\right\} \neq 0$ for benefit attribute, $y_{i j} \neq$ $0(i=1,2, \cdots, I)$ for cost attribute. The maximum value of the normalization attribute values is 1 , but the minimum value of the normalization attribute values is not always 0 . If the attribute value of the cost attribute is 0 , then this attribute value do not participate the minimum operation. The normalization value of attribute value 0 is 0 .

\subsection{Certitude structure transformation method}

Certainty factor is proposed by E.Short and B.Buchanan for MYCIN expert system in $1973{ }^{34}$. In order to construct the rule base of the expert system, the expert gives a number to each rule, this number is the degree of precision or certainty and it is named after the certainty factor of the rule. In this paper, the certainty factor is extended to the attribute value, and the certitude structure is given as:

$$
(y, c d)
$$

where $y$ is the flag value means the known fact and $y$ is called identity value; $c d$ is the certainty factor which represents the degree of certainty of $y$. Certitude structure is determined according to the cognition of human and representing the uncertainty of knowledge.
In some MADM problems, the attribute values may be given according to different data representations, such as real numbers, interval numbers, intuitionistic fuzzy numbers and linguistic variables. Suppose that each attribute has only one date representation, all of these attribute values should be transformed into certitude structure. According to the following definitions and principles:

(i) the definitions of interval numbers, intuitionistic fuzzy numbers and linguistic variables,

(ii) the similarity measure of interval values ${ }^{35}$,

(iii) the equivalence relation of the interval valued fuzzy set and intuitionistic fuzzy set ${ }^{36-37}$,

(iv) the diminishing marginal utility law ${ }^{38}$.

The certitude structure transformation method is given as follows.

Without loss of generality we suppose that all the attribute values are nonnegative numbers. Suppose that the attribute value $y_{i j}$ which is the value at alternative $A_{i}$ with respect to the $j$ th attribute $X_{j}$.

(i) real number

If $y_{i j}$ is a real number, then $y_{i j}$ is the exact number without uncertainty, and the certitude degree of $y_{i j}$ is 1 . In this case, the certitude structure of $y_{i j}$ is given as follows:

$$
\left(y_{i j}, 1\right) \text {. }
$$

(ii) interval number

If $y_{i j}$ is an interval number, then $y_{i j}$ can be given as $y_{i j}=\left[y_{i j}^{L}, y_{i j}^{U}\right]$, where $y_{i j}^{U}$ is the upper bound of $y_{i j}$, $y_{i j}^{L}$ is the lower bound of $y_{i j}, 0 \leqslant y_{i j}^{L} \leqslant y_{i j}^{U} . y_{i j}$ can be defined as $y_{i j}=\left\langle\frac{y_{i j}^{U}+y_{i j}^{L}}{2}, \frac{y_{i j}^{U}-y_{i j}^{L}}{2}\right\rangle$, where $\frac{y_{i j}^{U}+y_{i j}^{L}}{2}$ is the midpoint of $y_{i j}$ and $\frac{y_{i j}^{U}-y_{i j}^{L}}{2}$ is the radius of $y_{i j}$.

In this paper, the midpoint $\frac{y_{i j}^{U}+y_{i j}^{L}}{2}$ is assigned to the identity value of $y_{i j}^{U}$. In order to get the certitude degree of $y_{i j}^{U}$, we calculate the certitude degree of interval number $y_{i j}^{U}$, the upper bounds and lower bounds should be normalized into $[0,1]$ firstly. The only one thing to be noted here is that this step has nothing to do with the type of the attribute. The purpose of this step is to transmute interval number into interval value, and the best situation is that the transmutation meets the diminishing marginal utility law. 
According to the similarity measure of interval values ${ }^{35}$, the certitude degree can be given.

Suppose that the normalized value of $y_{i j}$ is $\left[\bar{y}_{i j}^{L}, \bar{y}_{i j}^{U}\right]$ and the normalized midpoint is $\bar{y}_{i j}^{M}=$ $\left[\bar{y}_{i j}^{M}, \bar{y}_{i j}^{M}\right]$, satisfied $\bar{y}_{i j}^{L} \leqslant \bar{y}_{i j}^{M} \leqslant \bar{y}_{i j}^{U}$. Then the similarity measure of $\left[\bar{y}_{i j}^{L}, \bar{y}_{i j}^{U}\right]$ and $\left[\bar{y}_{i j}^{M}, \bar{y}_{i j}^{M}\right]$ is as follows.

$$
\begin{aligned}
& S_{m}\left(\left[\bar{y}_{i j}^{L}, \bar{y}_{i j}^{U}\right],\left[\bar{y}_{i j}^{M}, \bar{y}_{i j}^{M}\right]\right) \\
& =1-\frac{1}{2}\left(\left|\bar{y}_{i j}^{L}-\bar{y}_{i j}^{M}\right|+\left|\bar{y}_{i j}^{U}-\bar{y}_{i j}^{M}\right|\right) \\
& =1-\frac{1}{2}\left(\bar{y}_{i j}^{M}-\bar{y}_{i j}^{L}+\bar{y}_{i j}^{U}-\bar{y}_{i j}^{M}\right) \\
& =1-\frac{1}{2}\left(\bar{y}_{i j}^{U}-\bar{y}_{i j}^{L}\right)
\end{aligned}
$$

and the certitude degree of $y_{i j}$ is $c d_{i j}=1-$ $\frac{1}{2}\left(\bar{y}_{i j}^{U}-\bar{y}_{i j}^{L}\right)$.

(iii) intuitionistic fuzzy number

If $y_{i j}$ is an intuitionistic fuzzy number, then it can be represented by $y_{i j}=\left\langle\mu\left(y_{i j}\right), \eta\left(y_{i j}\right)\right\rangle$, where $\mu\left(y_{i j}\right)$ is the degree of membership and $\eta\left(y_{i j}\right)$ is the degree of non-membership, $\mu\left(y_{i j}\right)+\eta\left(y_{i j}\right) \leqslant 1$.

Deschrijver et al. 36 and Chen et al. 37 had proved that there is an isomorphism mapping between the interval valued fuzzy set and intuitionistic fuzzy set. It means that there is an equivalence relationship between interval valued fuzzy set and intuitionistic fuzzy set, and $y_{i j}=\left\langle\mu\left(y_{i j}\right), \eta\left(y_{i j}\right)\right\rangle$ can be expressed as $y_{i j}=\left[\mu\left(y_{i j}\right), 1-\eta\left(y_{i j}\right)\right]$. The intuitionistic fuzzy number $y_{i j}$ can be transformed into certitude structure using the certitude structure transformation method of interval number.

(iv) linguistic variables

If $y_{i j}$ is a linguistic variable, then it is a member of a predefined linguistic term, such as $v=$ $\left\{v_{t} \mid t=1,2, \cdots, T\right\}, T$ is the number of the linguistic variables and it is an odd number. For $t \in$ $\{1,2, \cdots, T\}, r \in\{1,2, \cdots, T\}$ and $t>r$, we have $V_{t} \succ V_{r}$, where ' $\succ$ ' notes 'is better than'.

In the actual operation, the linguistic variable is often represented as interval number, triangular fuzzy number, trapezoidal fuzzy number or intuitionistic fuzzy number. For triangular fuzzy number and trapezoidal fuzzy number, they can be transformed into interval numbers with cut sets ${ }^{39}$, and the interval number can be transformed into certitude structure.

The following examples focusing on intuitionistic fuzzy number, linguistic variable can be expressed as intuitionistic fuzzy number with the corresponding relationship between linguistic term and intuitionistic fuzzy set. Table 1 is an example adapted from Refs. 40 and 41.

Table 1. Linguistic terms with 11 scales

\begin{tabular}{ll}
\hline Linguistic variables & $\begin{array}{l}\text { Intuitionistic } \\
\text { fuzzy number }\end{array}$ \\
\hline Extremely High, E & $<1.00,0.00>$ \\
Very Very High, VVH & $<0.90,0.10>$ \\
Very High, VH & $<0.80,0.10>$ \\
High, H & $<0.70,0.20>$ \\
Medium, High MH & $<0.60,0.30>$ \\
medium, M & $<0.50,0.40>$ \\
Medium Low, ML & $<0.40,0.50>$ \\
Low, L & $<0.25,0.60>$ \\
Very Low, VL & $<0.10,0.75>$ \\
Very Very Low, VVL & $<0.10,0.90>$ \\
Extremely Low, EL & $<0.00,1.00>$ \\
\hline
\end{tabular}

As linguistic variable can be expressed as intuitionistic fuzzy number, it also can be transformed into certitude structure.

\subsection{Certitude rule based inference method}

In this subsection, the Certitude Rule Based Inference Method using ER approach (CRIMER) is given.

Suppose $E=\left\{e_{t} \mid t=1,2, \cdots, T\right\}$ is the set of evidences $e_{t}$ with relative weight $w_{t}$ and certitude degree $c_{t}$, the proposition set $\Psi=\{\psi\}$ is the frame of discernment and $P(\Psi)=2^{\Psi}=\{\emptyset,\{\psi\}\}$, then the basic probability mass can be given as follows.

A basic probability mass is a function $m: 2^{\Psi} \rightarrow$ $[0,1]$, satisfying ${ }^{42}$ :

$$
\begin{gathered}
m(\emptyset)=0 \\
\sum_{H \subseteq \Psi} m(H)=1
\end{gathered}
$$

in other words

$m(\emptyset)+m(\Psi)+m(P(\Psi))=m(\Psi)+m(P(\Psi))=1$ 
Let

$$
m(\psi)=m(\{\psi\})=m(\Psi)
$$

then

$$
m(\psi)+m(P(\Psi))=1 .
$$

Based on the ER approach, the mass functions of evidence $e_{t}(t=1,2, \cdots, T)$ with relative weight $w_{t}$ and certitude degree $c_{t}$ is given as follows.

$$
\begin{gathered}
m_{t}(\psi)=w_{t} c_{t}, m_{t}(\emptyset)=0 \\
m_{t}(P(\Psi))=1-w_{t} c_{t}, \bar{m}_{t}(P(\Psi))=1-w_{t}
\end{gathered}
$$

where $m_{t}(\psi)$ is the basic probability mass caused by $e_{t} ; m_{t}(P(\Psi))$ is the remaining probability mass that is unassigned to $\Psi$ caused by the incompleteness of $e_{t} ; \bar{m}_{t}(P(\Psi))$ is amount of remaining support left uncommitted by the relative importance of $e_{t}$, coined as the residual support of $\Psi$ that cannot be assigned by $e_{t}$ alone due to its weight.

The set of the first $t(t=1,2, \cdots, T-1)$ evidences is $E_{\Gamma(t)}=\left\{e_{1}, e_{2}, \cdots, e_{t}\right\}$, the recursive combination formulas are as follows.

$$
\begin{gathered}
m_{\Gamma(1)}(\psi)=m_{1}(\psi)=w_{1} c_{1} \\
m_{\Gamma(1)}(\emptyset)=0 \\
m_{\Gamma(1)}(P(\Psi))=m_{1}(P(\Psi))=1-w_{1} c_{1} \\
\bar{m}_{\Gamma(1)}(P(\Psi))=\bar{m}_{1}(P(\Psi))=1-w_{1}
\end{gathered}
$$

the combination process can be developed into the following algorithm:

$$
\begin{gathered}
m_{\Gamma(t+1)}(\psi)=m_{\Gamma(t)}(\psi) m_{t+1}(\psi) \\
+m_{\Gamma(t)}(\psi) m_{t+1}(P(\Psi))+m_{\Gamma(t)}(P(\Psi)) m_{t+1}(\psi) \\
m_{\Gamma(t+1)}(P(\Psi))=m_{\Gamma(t)}(P(\Psi)) m_{t+1}(P(\Psi)) \\
\bar{m}_{\Gamma(t+1)}(P(\Psi))=\bar{m}_{\Gamma(t)}(P(\Psi)) \bar{m}_{t+1}(P(\Psi))
\end{gathered}
$$

the combined certitude degree is as follows:

$$
c=\frac{m_{\Gamma(T)}(\psi)}{1-\bar{m}_{\Gamma(T)}(P(\Psi))} .
$$

\section{Decision making method}

Suppose that a MADM-CD problem has $I$ alternatives $A_{i}(i=1,2, \cdots, I)$ and $J$ attributes $X_{j}(j=1,2, \cdots, J)$. The relative weights of the attributes are denoted by $W=\left(W_{1}, \cdots, W_{j}, \cdots, W_{J}\right)$, satisfying $0 \leqslant W_{j} \leqslant 1$ and $\sum_{j=1}^{J} W_{j}=1$. There are $S$ future states, and the probability of occurrence of the $s$ th $(s=1,2, \cdots, S)$ state is $p_{s}$. If there is a certitude structure $\left(x_{i j}^{s},\left(c d_{i j}^{s}\right)^{\prime}\right)$ for attribute $X_{j}$ of alternative $A_{i}$ with the sth state, then the final certitude degree $c f_{i j}^{s}$ for attribute $X_{j}$ of alternative $A_{i}$ with the sth state is given as the product of $p_{s}$ and $\left(c d_{i j}^{s}\right)^{\prime}$. The evaluation vector for attribute $X_{j}$ of alternative $A_{i}$ is:

$$
\left(X_{i j}, C D_{i j}\right)=\left(\left(x_{i j}^{1}, c d_{i j}^{1}\right),\left(x_{i j}^{2}, c d_{i j}^{2}\right), \cdots,\left(x_{i j}^{S}, c d_{i j}^{S}\right)\right)
$$

where $x_{i j}^{s}(s=1,2, \cdots, S)$ is the attribute value for attribute $X_{j}$ of alternative $A_{i}$ with the sth state, $c d_{i j}^{s}=$ $p_{s} \times\left(c d_{i j}^{s}\right)^{\prime}$ is the certitude degree of $x_{i j}^{s}, 0<c d_{i j}^{s}$ and $\sum_{s=1}^{S} c d_{i j}^{s} \leqslant 1$. The decision matrix is given as follows:

$$
\begin{aligned}
& \mathbf{D}_{M C D}= \\
& {\left[\begin{array}{cccc}
\left(X_{11}, C D_{11}\right) & \left(X_{12}, C D_{12}\right) & \cdots & \left(X_{1 J}, C D_{1 J}\right) \\
\left(X_{21}, C D_{21}\right) & \left(X_{22}, C D_{22}\right) & \cdots & \left(X_{2 J}, C D_{2 J}\right) \\
\vdots & \vdots & & \vdots \\
\left(X_{I 1}, C D_{I 1}\right) & \left(X_{I 2}, C D_{I 2}\right) & \cdots & \left(X_{I J}, C D_{I J}\right)
\end{array}\right]}
\end{aligned}
$$

Reference point is an important element of prospect theory. Decision goal, status quo and minimum requirements may be the more common occurring evaluating benchmark. In this paper, $O=$ $\left(o_{1}, \cdots, o_{j}, \cdots, o_{J}\right)$ is the reference points vector.

Heath et al. ${ }^{43}$ had argued that decision goals serve as reference points in a manner consistent with the value function of PT, and decision goals inherit the properties of the value function - not only a reference point, but also loss aversion and diminishing sensitivity. So in the paper, the decision goals can be served as reference points with MADM-CD with decision goals problem preferentially. 
Wakker and Zank ${ }^{44}$ proposed a value function; Prelec ${ }^{45}$ proposed a probability weight function from the axioms. On the basis of their research, the value function $v$ and certainty weight function $\pi$ for attribute $X_{j}$ of alternative $A_{i}$ with the sth state are given as follows.

$$
\begin{gathered}
v\left(\Delta x_{i j}^{s}\right)=\left\{\begin{array}{cc}
\delta\left(\Delta x_{i j}^{s}\right)^{\alpha}, & \Delta x_{i j}^{s} \geqslant 0 \\
-\theta\left(-\Delta x_{i j}^{s}\right)^{\beta}, & \Delta x_{i j}^{s}<0
\end{array}\right. \\
\pi\left(c d_{i j}^{s}\right)=\left\{\begin{array}{cc}
\exp \left\{-\left(-\ln c d_{i j}^{s}\right)^{\sigma^{+}}\right\}, & \Delta x_{i j}^{s} \geqslant 0 \\
\left.\exp \left\{-\ln c d_{i j}^{s}\right)^{\sigma^{-}}\right\}, & \Delta x_{i j}^{s}<0
\end{array}\right.
\end{gathered}
$$

where $\Delta x_{i j}^{s}$ is the gains or the losses for attribute $X_{j}$ of alternative $A_{i}$ with the sth state, $\Delta x_{i j}^{s}=x_{i j}^{s}-o_{j}$ for benefit attribute, $\Delta x_{i j}^{s}=o_{j}-x_{i j}^{s}$ for cost attribute. $\alpha$ and $\beta$ show the concave-convex degree of the region value function of the gains and the losses, respectively, where $\alpha>0, \beta>0$; if the decision maker is an adventurous decision maker then $\alpha>1$ and $\beta>1$, if the decision maker is an intermediate decision maker then $\alpha=\beta=1$, if the decision maker is a conservative decision maker then $0<\alpha<1$ and $0<\beta<1$. $\delta$ and $\theta$ show the decision maker is more sensitive to the gains or the losses; if the decision maker is more sensitive to the gains than the losses then $\delta>1$ and $\theta=1$, if the decision maker is more sensitive to the losses than the gains then $\delta=1$ and $\theta>1$. $\pi\left(c d_{i j}^{s}\right)$ is the certainty weight function of both the gains and the losses, satisfies all four target properties: risk aversion for gains and risk seeking for losses of high probability, risk seeking for gains, risk aversion for losses of low probability. For adventurous decision maker $0<\sigma^{-}<\sigma^{+}<1$, for an adventurous decision maker $0<\sigma^{+}<\sigma^{-}<1$, for an intermediate decision maker $\sigma^{+}=\sigma^{-}=1$; if $\sigma$ approaches 1 , then the certainty weight function approximates the linear, the expected utility case, if $\sigma$ approaches 0 , then the certainty weight function approximates a step function.

The value-weight matrix $\mathbf{V}_{W}$ is given as follows:

$$
\mathbf{V}_{W}=\left[\begin{array}{cccc}
\left(v\left(\Delta x_{11}\right), \pi\left(c d_{11}\right)\right) & \left(v\left(\Delta x_{12}\right), \pi\left(c d_{12}\right)\right) & \cdots & \left(v\left(\Delta x_{1 J}\right), \pi\left(c d_{1 J}\right)\right) \\
\left(v\left(\Delta x_{21}\right), \pi\left(c d_{21}\right)\right) & \left(v\left(\Delta x_{22}\right), \pi\left(c d_{22}\right)\right) & \cdots & \left(v\left(\Delta x_{2 J}\right), \pi\left(c d_{2 J}\right)\right) \\
\vdots & \vdots & & \vdots \\
\left(v\left(\Delta x_{I 1}\right), \pi\left(c d_{I 1}\right)\right) & \left(v\left(\Delta x_{I 2}\right), \pi\left(c d_{I 2}\right)\right) & \cdots & \left(v\left(\Delta x_{I J}\right), \pi\left(c d_{I J}\right)\right)
\end{array}\right]
$$

where

$$
\left(v\left(\Delta x_{i j}\right), \pi\left(c d_{i j}\right)\right)=\left(\left(v\left(\Delta x_{i j}^{1}\right), \pi\left(c d_{i j}^{1}\right)\right), \cdots,\left(v\left(\Delta x_{i j}^{S}\right), \pi\left(c d_{i j}^{S}\right)\right), \cdots,\left(v\left(\Delta x_{i j}^{S}\right), \pi\left(c d_{i j}^{S}\right)\right)\right) .
$$

The Prospect value $(\mathrm{Pv})$ for attribute $X_{j}$ of alternative $A_{i}$ with the sth state is given as follows:

$$
V_{i j}^{s}=v\left(\Delta x_{i j}^{s}\right) \pi\left(c d_{i j}\right)
$$

the prospect value matrix $\mathbf{P}_{M}$ is given as follows:

$$
\mathbf{P}_{M}=\left[\begin{array}{cccc}
V_{11} & V_{12} & \cdots & V_{1 J} \\
V_{21} & V_{22} & \cdots & V_{2 J} \\
\vdots & \vdots & & \vdots \\
V_{I 1} & V_{I 2} & \cdots & V_{I J}
\end{array}\right]
$$

where $V_{i j}=\left(V_{i j}^{1}, V_{i j}^{2}, \cdots, V_{i j}^{S}\right)$ is called Component Prospect value $(\mathrm{CPv})$.

$$
w_{i j}^{s}=\frac{\pi\left(c d_{i j}^{s}\right)}{\sum_{t=1}^{S} \pi\left(c d_{i j}^{t}\right)}
$$

With normalization method, the sth Normalized Prospect value $(\mathrm{NPv})$ for attribute $X_{j}$ of alternative $A_{i}$ is $\bar{V}_{i j}^{s}$; the sth Normalized Weight (NW) for each certainty weight $\pi\left(c d_{i j}\right)$ of the $i$ th alternative $A_{i}$ on the $j$ th attribute $X_{j}$ is $w_{i j}^{s}$ :

The prospect-weight matrix $\mathbf{P}_{W}$ of NPv and NW 
is given as follows:

$\mathbf{P}_{W}=\left[\begin{array}{cccc}\left(\bar{V}_{11}, w_{11}\right) & \left(\bar{V}_{12}, w_{12}\right) & \cdots & \left(\bar{V}_{1 J}, w_{1 J}\right) \\ \left(\bar{V}_{21}, w_{21}\right) & \left(\bar{V}_{22}, w_{22}\right) & \cdots & \left(\bar{V}_{2 J}, w_{2 J}\right) \\ \vdots & \vdots & & \vdots \\ \left(\bar{V}_{I 1}, w_{I 1}\right) & \left(\bar{V}_{I 2}, w_{I 2}\right) & \cdots & \left(\bar{V}_{I J}, w_{I J}\right)\end{array}\right]$

where $\left(\bar{V}_{i j}, w_{i j}\right)=\left(\left(\bar{V}_{i j}^{1}, w_{i j}^{1}\right),\left(\bar{V}_{i j}^{2}, w_{i j}^{2}\right), \cdots\right.$, $\left.\left(\bar{V}_{i j}^{S}, w_{i j}^{S}\right)\right), \bar{V}_{i j}$ is the Normalized Component Prospect value $(\mathrm{NCPv})$.

With CRIMER, $\bar{V}_{i j}^{s}(s=1,2, \cdots, S)$ serve as the degrees of belief for $X_{i j}$ in this paper, the reasons are as follows:

(i) the set $\Gamma_{i j}=\left\{\emptyset,\left\{A_{i j}\right\}\right\}$ is the frame of discernment, where $A_{i j}$ is the result of alternative $A_{i}$ on attribute $X_{j}$, and $\left(X_{i j}, C D_{i j}\right)$ is the evidence;

(ii) $\bar{V}_{i j}^{s}$ indicates that the great the NPv is, the better the alternative will be, this is consistent with the certitude degree;

(iii) $0 \leqslant \bar{V}_{i j}^{s} \leqslant 1(i=1,2, \cdots, I ; j=1,2, \cdots, J)$.

For the $i$ th alternative $A_{i}$, attribute prospect value $P_{i j}$ on the $j$ th attribute $X_{j}$ can be given as follows.

$$
\begin{gathered}
m_{i, s}\left(A_{i j}\right)=w_{i j}^{s} \bar{V}_{i j}^{s} \\
m_{i, s}(\emptyset)=0 \\
m_{i, s}\left(\Gamma_{i j}\right)=1-w_{i j}^{s} \bar{V}_{i j}^{s} \\
\bar{m}_{i, s}\left(\Gamma_{i j}\right)=1-w_{i j}^{s}
\end{gathered}
$$

where $m_{i, s}\left(A_{i j}\right)$ is the basic prospect assignment determined by $\left(X_{i j}, C D_{i j}\right) ; m_{i, s}\left(\Gamma_{i j}\right)$ is the remaining prospect assignment (or remaining probability mass) that is unassigned to $X_{j}$ caused by the incompleteness of $\left(X_{i j}, C D_{i j}\right) ; \bar{m}_{i, s}\left(\Gamma_{i j}\right)$ is the remaining support left uncommitted by $\left(X_{i j}, C D_{i j}\right)$.

When $s=1$,

$$
\begin{gathered}
m_{i, T(1)}\left(A_{i j}\right)=m_{i, 1}\left(A_{i j}\right)=w_{i j}^{1} \bar{V}_{i j}^{1} \\
m_{i, T(1)}(\emptyset)=m_{i, 1}(\emptyset)=0 \\
m_{i, T(1)}\left(\Gamma_{i j}\right)=m_{i, 1}\left(\Gamma_{i j}\right)=1-w_{i j}^{1} \bar{V}_{i j}^{1}
\end{gathered}
$$

$$
\bar{m}_{i, T(1)}\left(\Gamma_{i j}\right)=\bar{m}_{i, 1}\left(\Gamma_{i j}\right)=1-w_{i j}^{1}
$$

then the combination process is as follows:

$$
\begin{gathered}
m_{i, T(s+1)}\left(A_{i j}\right)=m_{i, T(s)}\left(A_{i j}\right) m_{i, s+1}\left(A_{i j}\right) \\
+m_{i, T(s)}\left(A_{i j}\right) m_{i, s+1}\left(\Gamma_{i j}\right)+m_{i, T(s)}\left(\Gamma_{i j}\right) m_{i, s+1}\left(A_{i j}\right) \\
m_{i, T(s+1)}\left(\Gamma_{i j}\right)=m_{i, T(s)}\left(\Gamma_{i j}\right) m_{i, s+1}\left(\Gamma_{i j}\right) \\
\bar{m}_{i, T(s+1)}\left(\Gamma_{i j}\right)=\bar{m}_{i, T(s)}\left(\Gamma_{i j}\right) \bar{m}_{i, s+1}\left(\Gamma_{i j}\right) \\
P_{i j}=\frac{m_{i, T(S)}\left(A_{i j}\right)}{1-\bar{m}_{i, T(S)}\left(\Gamma_{i j}\right)} .
\end{gathered}
$$

The attribute prospect value matrix $\mathbf{M}_{A P}$ is composed of all prospect values:

$$
\mathbf{M}_{A P}=\left[\begin{array}{cccc}
P_{11} & P_{12} & \cdots & P_{1 J} \\
P_{21} & P_{22} & \cdots & P_{2 J} \\
\vdots & \vdots & & \vdots \\
P_{I 1} & P_{I 2} & \cdots & P_{I J}
\end{array}\right]
$$

With CRIMER, the attribute prospect value $P_{i j}$ serve as the degrees of belief for alternative $A_{i}$ on attribute $X_{j}$ in this paper, the reasons are as follows:

(i) the power set $\Lambda_{i}=\left\{\emptyset,\left\{A_{i}\right\}\right\}$ of the single proposition set of $\left\{A_{i}\right\}$, alternative $A_{i}$ is the frame of discernment, and $X^{i}=$ $\left\{\left(X_{i 1}, C D_{i 1}\right), \cdots,\left(X_{i j}, C D_{i j}\right), \cdots,\left(X_{i J}, C D_{i J}\right)\right\}$ is the evidence set;

(ii) the attribute prospect value $P_{i j}$ indicates that the great the normalized prospect value is, the better the alternative will be, this is consistent with the degree of certainty;

(iii) the evidence $\left(X_{i j}, C D_{i j}\right)$ for attribute $X_{j}$ of alternative $A_{i}$ is a meaningful and independent evaluation standard for describing decision result;

(iv) $0 \leqslant P_{i j} \leqslant 1,(i=1,2, \cdots, I ; j=1,2, \cdots, J)$.

The combination decision prospect value $V\left(A_{i}\right)$ of alternative $A_{i}$ can be given as follows.

$$
\begin{gathered}
m_{j}\left(A_{i}\right)=W_{j} P_{i j} \\
m_{j}(\emptyset)=0 \\
m_{j}\left(\Lambda_{i}\right)=1-W_{j} P_{i j} \\
\bar{m}_{j}\left(\Lambda_{i}\right)=1-W_{j}
\end{gathered}
$$


where $m_{j}\left(A_{i}\right)$ is the basic prospect assignment (also known as basic probability mass) caused by $\left(x_{i j}, c d_{i j}\right) ; m_{j}\left(\Lambda_{i}\right)$ is the remaining prospect assignment that is unassigned to $\left\{A_{i}\right\}$ caused by the incompleteness of $\left(x_{i j}, c d_{i j}\right) ; \bar{m}_{j}\left(\Lambda_{i}\right)$ is the remaining support left uncommitted by $\left(x_{i j}, c d_{i j}\right)$.

When $s=1$,

$$
\begin{gathered}
m_{T(1)}\left(A_{i}\right)=m_{1}\left(A_{i}\right)=W_{1} P_{i 1} \\
m_{I(1)}(\emptyset)=m_{1}(\emptyset)=0 \\
m_{T(1)}\left(\Lambda_{i}\right)=m_{1}\left(\Lambda_{i}\right)=1-W_{1} P_{i 1} \\
\bar{m}_{T(1)}\left(\Lambda_{i}\right)=\bar{m}_{1}\left(\Lambda_{i}\right)=1-W_{1}
\end{gathered}
$$

then the combination process is as follows:

$$
\begin{gathered}
m_{T(j+1)}\left(A_{i}\right)=m_{T(j)}\left(A_{i}\right) m_{j+1}\left(A_{i}\right) \\
+m_{T(j)}\left(A_{i}\right) m_{j+1}\left(\Lambda_{i}\right)+m_{T(j)}\left(\Lambda_{i}\right) m_{j+1}\left(A_{i}\right) \\
m_{T(j+1)}\left(\Lambda_{i}\right)=m_{T(j)}\left(\Lambda_{i}\right) m_{j+1}\left(\Lambda_{i}\right) \\
\bar{m}_{T(j+1)}\left(\Lambda_{i}\right)=\bar{m}_{T(j)}\left(\Lambda_{i}\right) \bar{m}_{j+1}\left(\Lambda_{i}\right) \\
V\left(A_{i}\right)=\frac{m_{T(J)}\left(A_{i}\right)}{1-\bar{m}_{T(J)}\left(\Lambda_{i}\right)} .
\end{gathered}
$$

Obviously, the combination decision prospect value indicates that the greater the combination decision prospect value $V\left(A_{i}\right)$ is, the better the alternative $A_{i}$ will be. As a result, in accordance to a descending order of the overall combination decision prospect values of all alternatives, we can determine the ranking order of all alternatives or select the desirable alternative(s) from the alternative set.
In summary, the procedure of the PT-ER method for MADM-CD problem is given as follows.

Step 1 Structure value function $v$ and certainty weight function $\pi$.

Step 2 Get the prospect-weight matrix $\mathbf{P}_{W}$.

Step 3 Calculate the attribute prospect values using CRIMER, and get the attribute prospect value matrix $\mathbf{M}_{A P}$.

Step 4 Calculate the combination decision prospect values $V\left(A_{i}\right)$ using CRIMER.

Step 5 Determine the ranking order of all alternatives or select the desirable alternative(s).

\section{Illustration examples}

In this section, two examples are given to illustrate the feasibility and validity of the PT-ER method by comparing with some existing approaches.

\subsection{The assessment of tactical missiles}

In this subsection, we will utilize an example (adapted from Ref. 41) involving the assessments for five tactical missiles to illustrate the developed methods. The weapons suppliers provided some information of these five tactical missiles after investigate. According to Table 1, the experts provide the specifications of these five tactical missiles shown in Table 2. With the certitude structure transformation method (Subsection 2.2) the specifications of these five tactical missiles with certitude degrees shown in Table 3 (based on vector normalization method).

Table 2. Specifications of tactical missiles

\begin{tabular}{ccccccc}
\hline Types & $\begin{array}{c}\text { Accuracy } \\
\left(X_{1}, \mathrm{~km}\right)\end{array}$ & $\begin{array}{c}\text { Payload } \\
\left(X_{2}, \mathrm{~kg}\right)\end{array}$ & $\begin{array}{c}\text { Mobility } \\
\left(X_{3}, \mathrm{~km} / \mathrm{h}\right)\end{array}$ & $\begin{array}{c}\text { Price } \\
\left(X_{4}, 10^{6} \$\right)\end{array}$ & $\begin{array}{c}\text { Reliability } \\
\left(X_{5}\right)\end{array}$ & $\begin{array}{c}\text { Maintainability } \\
\left(X_{6}\right)\end{array}$ \\
\hline Tactical Missile $1 A_{1}\left(x_{1 j}, c d_{1 j}\right)$ & 2.0 & 500 & {$[55,56]$} & {$[4.7,5.7]$} & $\mathrm{M}$ & $\mathrm{VH}$ \\
Tactical Missile 2 $A_{2}\left(x_{2 j}, c d_{2 j}\right)$ & 2.5 & 540 & {$[30,40]$} & {$[4.2,5.2]$} & $\mathrm{L}$ & $\mathrm{M}$ \\
Tactical Missile 3 $A_{3}\left(x_{3 j}, c d_{3 j}\right)$ & 1.8 & 480 & {$[50,60]$} & {$[5.0,6.0]$} & $\mathrm{H}$ & $\mathrm{H}$ \\
Tactical Missile 4 $A_{4}\left(x_{4 j}, c d_{4 j}\right)$ & 2.2 & 520 & {$[35,45]$} & {$[4.5,5.5]$} & $\mathrm{M}$ & $\mathrm{M}$ \\
Tactical Missile 5 $A_{5}\left(x_{5 j}, c d_{5 j}\right)$ & 3.0 & 580 & {$[30,35]$} & {$[4.8,5.5]$} & $\mathrm{MH}$ & $\mathrm{MH}$ \\
Weight & 0.2 & 0.2 & 0.1 & 0.1 & 0.2 & 0.2 \\
\hline
\end{tabular}


Table 3. Specifications of tactical missiles (with certitude degree)

\begin{tabular}{ccccccc}
\hline Types & $\begin{array}{c}\text { Accuracy } \\
\left(X_{1}, \mathrm{~km}\right)\end{array}$ & $\begin{array}{c}\text { Payload } \\
\left(X_{2}, \mathrm{~kg}\right)\end{array}$ & $\begin{array}{c}\text { Mobility } \\
\left(X_{3}, \mathrm{~km} / \mathrm{h}\right)\end{array}$ & $\begin{array}{c}\text { Price } \\
\left(X_{4}, 10^{6} \$\right)\end{array}$ & $\begin{array}{c}\text { Reliability } \\
\left(X_{5}\right)\end{array}$ & $\begin{array}{c}\text { Maintainability } \\
\left(X_{6}\right)\end{array}$ \\
\hline $\begin{array}{c}\text { Tactical Missile } 1 \\
A_{1}\left(X_{1 j}, C D_{1 j}\right)\end{array}$ & $(2.0,1)$ & $(500,1)$ & $(55.5,0.9652)$ & $(5.20,0.9163)$ & $(0.550,0.9005)$ & $(0.850,0.9526)$ \\
$\begin{array}{c}\text { Tactical Missile } 2 \\
A_{2}\left(X_{2 j}, C D_{2 j}\right)\end{array}$ & $(2.5,1)$ & $(540,1)$ & $(35.0,0.8732)$ & $(4.70,0.9023)$ & $(0.325,0.7234)$ & $(0.550,0.9096)$ \\
$\begin{array}{c}\text { Tactical Missile 3 } \\
A_{3}\left(X_{3 j}, C D_{3 j}\right)\end{array}$ & $(1.8,1)$ & $(480,1)$ & $(55.0,0.9376)$ & $(5.50,0.9233)$ & $(0.750,0.9345)$ & $(0.750,0.9432)$ \\
$\begin{array}{c}\text { Tactical Missile } 4 \\
A_{4}\left(X_{4 j}, C D_{4 j}\right)\end{array}$ & $(2.2,1)$ & $(520,1)$ & $(40.0,0.8971)$ & $(5.00,0.9112)$ & $(0.550,0.9005)$ & $(0.550,0.9096)$ \\
$\begin{array}{c}\text { Tactical Missile 5 } \\
A_{5}\left(X_{5 j}, C D_{5 j}\right)\end{array}$ & $(3.0,1)$ & $(580,1)$ & $(32.5,0.9025)$ & $(5.15,0.9285)$ & $(0.650,0.9208)$ & $(0.650,0.9299)$ \\
Weight & 0.2 & 0.2 & 0.1 & 0.1 & 0.2 & 0.2 \\
\hline
\end{tabular}

This is a MADM-CD problem with single state, involving five alternatives and six attributes without decision goal. Attribute Price $\left(X_{4}\right)$ is a cost attribute, and the others are benefit ones. As the decision goal is not given, we using current minimum requirements (the worst attribute value of all alternatives) as reference points and apply the PT-ER method to the ranking and selection of the alternative tactical missiles below.

Current minimum requirements reference points is $O=(1.8,480,32,5.5,0.325,0.55)$.

Step 1 Structure value function $v$ and weight function $\pi$.

For conservative decision maker, suppose that this decision maker is more sensitive to the gains than the losses, then with Refs. 45 and 46 the value function and weight function can be given as follows:

$$
\begin{gathered}
v\left(\Delta x_{i j}\right)=\left\{\begin{array}{cl}
\left(\Delta x_{i j}\right)^{1.21}, & \Delta x_{i j} \geqslant 0 \\
-2.25\left(-\Delta x_{i j}\right)^{1.02}, & \Delta x_{i j}<0
\end{array}\right. \\
\pi\left(c f_{i j}\right)=\left\{\begin{array}{cc}
\exp \left\{-\left(-\ln c d_{i j}\right)^{0.603}\right\}, & \Delta x_{i j} \geqslant 0 \\
\exp \left\{-\left(-\ln c d_{i j}\right)^{0.605}\right\}, & \Delta x_{i j}<0
\end{array}\right.
\end{gathered}
$$

The value-weight matrix $\mathbf{V}_{W}$ is given as follows:

$\mathbf{V}_{W}=$

$$
\left[\begin{array}{cccccc}
(0.1426,1) & (37.5186,1) & (45.6029,0.8759) & (0.2330,0.7954) & (0.1645,0.7746) & (0.2330,0.5180) \\
(0.6495,1) & (141.7630,1) & (3.7785,0.7419) & (0.7634,0.7768) & (0,0.6032) & (0,0.7864) \\
(0,1) & (0,1) & (44.4315,0.8267) & (0,0.8043) & (0.3551,0.8219) & (0.1426,0.8357) \\
(0.3300,1) & (86.7946,1) & (12.3805,0.7703) & (0.4323,0.7885) & (0.1645,0.7746) & (0,0.7864) \\
(1.2468,1) & (263.0268,1) & (0.4323,0.7771) & (0.2808,0.8128) & (0.2567,0.8017) & (0.0617,0.8149)
\end{array}\right]
$$

Step 2 Get the prospect-weight matrix $\mathbf{P}_{W}$.

The prospect values can be given with $V_{i j}=$ $v\left(\Delta x_{i j}\right) \pi\left(c d_{i j}\right)$, the prospect value matrix $\mathbf{P}_{M}$ is given as:

$$
\mathbf{P}_{M}=\left[\begin{array}{cccccc}
0.1426 & 37.5186 & 39.9427 & 0.1853 & 0.1274 & 0.1985 \\
0.6495 & 141.7630 & 2.8033 & 0.5930 & 0 & 0 \\
0 & 0 & 36.7309 & 0 & 0.2918 & 0.1192 \\
0.3300 & 86.7946 & 9.564 & 0.3408 & 0.1274 & 0 \\
1.2468 & 263.0268 & 0.3359 & 0.2282 & 0.2058 & 0.0502
\end{array}\right]
$$


As there is only one state in this example, the NW is 1. With the range-logarithm normalization

$$
\mathbf{P}_{W}=\left[\begin{array}{cccccc}
(0.1563,1) & (0.1924,1) & (1.0000,1) & (0.3923,1) & (0.5226,1) & (1.0000,1) \\
(0.6049,1) & (0.6220,1) & (0.0872,1) & (1.0000,1) & (0,1) & (0,1) \\
(0,1) & (0,1) & (0.9403,1) & (0,1) & (1.0000,1) & (0.6787,1) \\
(0.3387,1) & (0.4114,1) & (0.3013,1) & (0.6551,1) & (0.5226,1) & (0,1) \\
(1.0000,1) & (1.0000,1) & (0,1) & (0.4697,1) & (0.7698,1) & (0.3256,1)
\end{array}\right] .
$$

Step 3 Get the attribute prospect value matrix $\mathbf{M}_{A P}$. With CRIMER, the attribute prospect value

$$
\mathbf{M}_{A P}=\left[\begin{array}{cccccc}
0.1563 & 0.1924 & 1.0000 & 0.3923 & 0.5226 & 1.0000 \\
0.6049 & 0.6220 & 0.0872 & 1.0000 & 0 & 0 \\
0 & 0 & 0.9403 & 0 & 1.0000 & 0.6787 \\
0.3387 & 0.4114 & 0.3013 & 0.6551 & 0.5226 & 0 \\
1.0000 & 1.0000 & 0 & 0.4697 & 0.7698 & 0.3256
\end{array}\right] .
$$

Step 4 Calculate the combination decision prospect values $V\left(A_{i}\right)$ using CRIMER The combination decision prospect values are as follows: $V\left(A_{1}\right)=0.6333, V\left(A_{2}\right)=0.4689, V\left(A_{3}\right)=0.5591$, $V\left(A_{4}\right)=0.4574, V\left(A_{5}\right)=0.7745$.

According to $V\left(A_{i}\right)(i=1,2,3,4,5)$, the alternative tactical missiles: $A_{5} \succ A_{1} \succ A_{3} \succ A_{4} \succ A_{2}$. Thus, tactical missiles $A_{5}$ should be further developed. In Ref. 41, the rank is $A_{3} \succ A_{1} \succ A_{5} \succ A_{4} \succ A_{2}$ and tactical missiles $A_{3}$ should be further developed.

If the decision maker is an intermediate decision maker, then the combination decision prospect values are as follows:

$$
\begin{gathered}
V\left(A_{1}\right)=0.6771, V\left(A_{2}\right)=0.5002, V\left(A_{3}\right)=0.5729, \\
V\left(A_{4}\right)=0.5206, V\left(A_{5}\right)=0.7987 .
\end{gathered}
$$

The alternative tactical missiles: $A_{5} \succ A_{1} \succ A_{3} \succ$ $A_{4} \succ A_{2}$. Thus, tactical missiles $A_{5}$ should be further developed. In Ref. 41, the rank is $A_{1} \succ A_{5} \succ A_{3} \succ$ $A_{4} \succ A_{2}$ and tactical missiles $A_{1}$ should be further developed.

If the decision maker is an adventurous decision maker, then the combination decision prospect values are as follows:

$$
\begin{gathered}
V\left(A_{1}\right)=0.7009, V\left(A_{2}\right)=0.5163, V\left(A_{3}\right)=0.5753, \\
V\left(A_{4}\right)=0.5495, V\left(A_{5}\right)=0.8100 .
\end{gathered}
$$

The alternative tactical missiles: $A_{5} \succ A_{1} \succ A_{3} \succ$ $A_{4} \succ A_{2}$. Thus, tactical missiles $A_{5}$ should be further developed. In Ref. 41, the rank is $A_{1} \succ A_{3} \succ A_{5} \succ$ $A_{4} \succ A_{2}$ and tactical missiles $A_{1}$ should be further method, the prospect-weight matrix $\mathbf{P}_{W}$ is given as:

matrix $\mathbf{M}_{A P}$ is as follows:

developed.

In order to show the performance of PT-ER method, we compare the three optimal alternatives $A_{1}, A_{3}$ and $A_{5}$ based on Table 2.

(i) Compare alternative $A_{1}$ and alternative $A_{3}$. Except the fifth attribute Reliability $\left(X_{5}\right)$, alternative $A_{3}$ is no match for alternative $A_{1}$ on the other attributes. So it is more reasonable that alternative $A_{1}$ is better than alternative $A_{3}$.

(ii) Compare alternative $A_{1}$ and alternative $A_{5}$. Except the third attribute $\operatorname{Mobility}\left(X_{3}\right)$ and the sixth attribute Maintainability $\left(X_{6}\right)$, alternative $A_{1}$ is no match for alternative $A_{5}$ on the other attributes, especially on the first attribute $\operatorname{Accuracy}\left(X_{1}\right)$ and the second attribute Payload $\left(X_{2}\right)$. Moreover, although alternative $A_{1}$ is better than alternative $A_{5}$ on the third attribute Mobility $\left(X_{3}\right)$, the weight of the third attribute Mobility $\left(X_{3}\right)$ is less than others and the third attribute Mobility $\left(X_{3}\right)$ has no obvious effect. So it is more reasonable that alternative $A_{5}$ is better than alternative $A_{1}$.

In conclusion, for this example, PT-ER method is feasibility and validity, and better than the decision making method in Ref. 41. 


\subsection{The investment of aviation equipment}

In this subsection, we will analysis an example (adapted from Ref.47) involving the assessments for four aviation equipment investment alternatives to illustrate the developed methods. There are four attributes: Promote national security expectation (PNSE $(\%)$ ), Promote military technology progress (PMTP $(\%)$ ), Promote relevant industries development (PRID(\%)) and Developed time (DT(10years)). Due to the uncertainty of the international situation in the future, supposed that there are three potential states: Stable international environment, Local small war, Large skirmish. The project indicators of these four equipment investment alternatives are shown in Table 4.

This is a MADM-CD problem, involving four alternatives and four attributes without decision goal. Attribute Time $\left(X_{4}\right)$ is a cost attribute, and the others are benefit ones. The attributes are under three potential states:
$S_{1}$ : Stable international environment;

$S_{2}$ : Local small war;

$S_{3}$ : Large skirmish.

Because of the decision goal and attribute weights are not given, to solve this issue, we using current minimum requirements as reference points and average weights to the ranking and selection of the alternative tactical missiles below.

Current minimum requirements reference points are $O=(0.4,0.4,0.55,0.8)$ and attribute weights are $W=(0.25,0.25,0.25,0.25)$. For a conservative decision maker, the attribute prospect values are shown in Table 5.

The combination decision prospect values as follows:

$$
\begin{aligned}
& V\left(A_{1}\right)=0.4556, V\left(A_{2}\right)=0.6696, \\
& V\left(A_{3}\right)=0.5580, V\left(A_{4}\right)=0.6908 .
\end{aligned}
$$

According to $V\left(A_{i}\right)(i=1,2,3,4)$, the aviation equipment investment alternatives: $A_{4} \succ A_{2} \succ A_{3} \succ$ $A_{1}$, Thus, aviation equipment investment alternative $A_{4}$ should be accepted.

Table 4. The project indicators of equipment investment alternatives under different states (with certitude degrees)

\begin{tabular}{ccccc}
\hline Alternatives & $\begin{array}{c}\text { PNSE } \\
\left(X_{1}, \%\right)\end{array}$ & $\begin{array}{c}\text { PMTP } \\
\left(X_{2}, \%\right)\end{array}$ & $\begin{array}{c}\text { PRID } \\
\left(X_{3}, \%\right)\end{array}$ & $\begin{array}{c}\text { DT } \\
\left(X_{4}, 10 \text { years }\right)\end{array}$ \\
\hline Alternative 1 & $((40,0.540)$, & $((65,0.570)$, & $((55,0.570)$, & $((0.80,0.540)$, \\
$A_{1}\left(X_{1 j}, C D_{1 j}\right)$ & $(60,0.270)$, & $(45,0.285)$, & $(70,0.270)$, & $(0.75,0.255)$, \\
& $(80,0.09))$ & $(45,0.095))$ & $(65,0.085))$ & $(0.70,0.09))$ \\
Alternative 2 & $((55,0.570)$, & $((50,0.540)$, & $((70,0.540)$, & $((0.65,0.570)$, \\
$A_{2}\left(X_{2 j}, C D_{2 j}\right)$ & $(55,0.285)$, & $(65,0.285)$, & $(65,0.255)$, & $(0.60,0.270)$, \\
& $(50,0.090))$ & $(75,0.095))$ & $(60,0.090))$ & $(0.65,0.095))$ \\
Alternative 3 & $((85,0.570)$, & $((40,0.480)$, & $((60,0.540)$, & $((0.70,0.540)$, \\
$A_{3}\left(X_{3 j}, C D_{3 j}\right)$ & $(80,0.270)$, & $(45,0.255)$, & $(60,0.270)$, & $(0.50,0.270)$, \\
& $(75,0.085))$ & $(55,0.095))$ & $(60,0.090))$ & $(0.75,0.085))$ \\
Alternative 4 & $((65,0.570)$, & $((55,0.570)$, & $((55,0.570)$, & $((0.45,0.570)$, \\
$A_{4}\left(X_{4 j}, C D_{4 j}\right)$ & $(60,0.270)$, & $(55,0.255)$, & $(70,0.270)$, & $(0.65,0.285)$, \\
& $(65,0.095))$ & $(50,0.080))$ & $(75,0.095))$ & $(0.55,0.085))$ \\
\hline
\end{tabular}

Table 5. The attribute prospect values

\begin{tabular}{ccccc}
\hline Alternatives & PNSE $\left(X_{1}\right)$ & PMTP $\left(X_{2}\right)$ & PRID $\left(X_{3}\right)$ & DT $\left(X_{4}\right)$ \\
\hline Alternative $1 A_{1}$ & 0.2298 & 0.7251 & 0.3728 & 0.0641 \\
Alternative $2 A_{2}$ & 0.3337 & 0.6361 & 0.8084 & 0.4733 \\
Alternative $3 A_{3}$ & 0.8673 & 0.1268 & 0.3446 & 0.4299 \\
Alternative $4 A_{4}$ & 0.5344 & 0.5820 & 0.4423 & 0.7940 \\
\hline
\end{tabular}


If the decision maker is an intermediate decision maker, the combination decision prospect values as follows:

$$
\begin{aligned}
& V\left(A_{1}\right)=0.4114, V\left(A_{2}\right)=0.6389, \\
& V\left(A_{3}\right)=0.5277, V\left(A_{4}\right)=0.6508 .
\end{aligned}
$$

The aviation equipment investment alternatives: $A_{4} \succ A_{2} \succ A_{3} \succ A_{1}$, Thus, aviation equipment investment alternative $A_{4}$ should be accepted.

If the decision maker is an adventurous decision maker, the combination decision prospect values as follows:

$$
\begin{aligned}
& V\left(A_{1}\right)=0.4850, V\left(A_{2}\right)=0.7290, \\
& V\left(A_{3}\right)=0.6177, V\left(A_{4}\right)=0.7295 .
\end{aligned}
$$

The aviation equipment investment alternatives: $A_{4} \succ A_{2} \succ A_{3} \succ A_{1}$, Thus, aviation equipment investment alternative $A_{4}$ should be accepted.

In general, the ranking order of aviation equipment investment alternatives is $A_{4} \succ A_{2} \succ A_{3} \succ A_{1}$ and the aviation equipment investment alternative $A_{4}$ should be accepted. In Ref. 47, the ranking order is $A_{2} \succ A_{3} \succ A_{1} \succ A_{4}$ and aviation equipment investment alternative $A_{2}$ should be accepted.

There is a really big disparity in the ranking order of alternative $A_{4}$, this is because that in Ref. 47 , the defaults of attribute types are benefit attributes, this is not appropriate and realistic. (If DT is a benefit attribute, then the optimal attribute is $A_{2}$ and the worst one is $A_{4}$ based on the PT-ER method with average weights).

In conclusion, the PT-ER method is feasibility and validity with higher stability. As the decision making method in Ref. 47 do not distinguish the benefit attribute and cost attribute, and do not consider the weights of attributes and the types of decision makers, the superiority of the PT-ER method is also illustrate.

\section{Conclusion}

The multi-attribute decision making problems often need to deal with decision making information with uncertainty. During the last two decades, a number of researchers have proposed and developed the evidential reasoning approach to deal with this problems with both quantitative and qualitative attributes. But those researchers modeling based on the expected utility theory which systematically deviate from the individual behavior in real world.

Therefore, in this paper, based on the certitude structure, we proposed a novel method to solve the MADM problems where attribute values are hybrid types with uncertainty. Firstly, we describe the decision making behavior of decision maker using the prospect theory which is the competing theory to expected utility theory by Kahneman and Tversky ${ }^{16,23}$. Then, a certitude structure transformation method is developed to transform different data representations into certitude structure to describe uncertainty. Finally, the PT-ER method is proposed based on prospect theory and evidential reasoning approach. To test our methods effectiveness, we compare the alternative rankings with the conclusions of Guo ${ }^{41}$ and $\mathrm{Li}^{47}$ in Section 4, we can find that the PT-ER method is more rational and effective.

\section{Acknowledgement}

This work is supported by National Science Foundation of China (Grant No. 61175055, 61305074), Sichuan Science and Technology Innovation Talent Project (Grant No. 2014-057).

\section{References}

1. N. J. Nillsson. Probabilistic logic. Artificial Intelligence, 28: 71-87 (1986).

2. L. A. Zadeh. Fuzzy set. Information and Control, 8: 338-353 (1965).

3. J. L. Deng. Control problem of Grey System. Systems and Control Letters, 1(5): 288-294 (1982).

4. Z. Pawlak. Rough sets. International Journal of Computer and Information Sciences, 11(5): 341-356 (1982).

5. Z. S. Xu, Q. L. Da. An overview of operators for aggregating. International Journal of Intelligent Systems, 18: 953-969 (2003).

6. G. Y. Wang. Unascertained information and its mathematical treatment. Journal of Harbing Engineering University, 4(23): 1-9 (1990). (in Chinese)

7. Y. Xu, J. Liu, L. Martłnez, D. Ruan. Some views on information fusion and logic based approaches in decision making under uncertainty. Journal of Universal Computer Science. 16(1): 3-21 (2010).

8. J. Q. Wang, R. R. Nie, H. Y. Zhang, X. H. Chen. Intuitionistic fuzzy multi-criteria decision-making method 
based on evidential reasoning. Applied Soft Computing, 13: 1823-1831 (2013).

9. K. S. Chin, C. Fu. Integrated evidential reasoning approach in the presence of cardinal and ordinal preferences and its applications in software selection. Expert Systems with Applications, 41: 6718-6727 (2014).

10. S. Yao, W. Q. Huang. Induced ordered weighted evidential reasoning approach for multiple attribute decision analysis with uncertainty. International Journal of Intelligent Systems, 29: 906-925 (2014).

11. I. Montes, E. Miranda, S. Montes. Decision making with imprecise probabilities and utilities by means of statistical preference and stochastic dominance. European Journal of Operational Research, 234: 209-220 (2014).

12. C. Park, S. Ahn, S. Lee. A bayesion decision model based on expected utility and uncertainty risk. Applied Mathematics and Computation, 242: 643-648 (2014).

13. C. Fu, S. L. Yang. An evidential reasoning based consensus model for multiple attribute group decision analysis problems with interval-valued group consensus requirements. European Journal of Operational Research, 223: 167-176 (2012).

14. M. Guo, J. B. Yang, K. S. Chin, H. W. Wang. Evidential reasoning based preference programming for multiple attribute decision analysis under uncertainty. $E u$ ropean Journal of Operational Research, 182: 1294 1312 (2007).

15. J. von Neumann, O. Morgenstem. Theory of games and economic behavior. Princeton: Princeton University Press, (1944).

16. D. Kahneman, A. Tversky. Prospect Theory: An analysis of decision under risk. Econometrica, 47(2): 263 291 (1979).

17. G. Gurevich, D. Kliger, O. Levy. Decision-making under uncertainty-A field study of cumulative prospect theory. Journal of Banking and Finance, 33: 1221-1229 (2009).

18. P. Liu, F. Jin, X. Zhang, et al. Research on the multi-attribute decision-making under risk with interval probability based on prospect theory and the uncertain linguistic variables. Knowledge-Based Systems, 24: 554-561 (2011).

19. A. E. Attema, W. B. F. Brouwer, O. 1Haridon. Prospect theory in the health domain: A quantitative assessment. Journal of Health Economics, 32: 1057-1065 (2013).

20. U. Schmidt, H. Zank. A simple model of cumulative prospect theory. Journal of Mathematical Economics, 45(3): 308-319 (2009).

21. E. Kemel, C. Paraschiv. Prospect theory for joint time and money consquences in risk and ambiguity. Transportation Research Part B, 56: 81-95 (2013).

22. S. Dhami, A. al-Nowaihi. Why do people pay taxes? Prospect theory versus expected utility theory. Journal of Economic Behavior and Organization, 64: 171-192 (2007).

23. A. Tversky, D. Kahneman. Advances in Prospect Theory: Cumulative representation of uncertainty. Journal of Risk and Uncertainty, 5: 297-323 (1992).

24. J. B. Yang. Rule and utility based evidential reasoning approach for multiattribute decision analysis under uncertainties. European Journal of Operational Research, 131: 31-61 (2001).

25. J. B. Yang, D. L. Xu. On the evidential reasoning algorithm for multiple attribute decision analysis under uncertainty. IEEE Transactions on Systems, Man, and Cybernetics-Part A: Systems and Humans,32(3): 289-304 (2002).

26. J. B. Yang, D. L. Xu. Nonlinear information aggregation via evidential reasoning in multiattribute decision analysis under uncertainty. IEEE Transactions on Systems, Man, and Cybernetics-Part A: Systems and Humans, 32(3): 376-393 (2002).

27. J. B. Yang, D. L. Xu. Evidential reasoning rule for evidence combination. Artificial Intelligence, 205: 1-29 (2013).

28. J. B. Yang, M. G. Singh. An evidential reasoning approach for multiple-attribute decision making with uncertainty. IEEE Transactions on Systems, Man, and Cybernetics, 24(1): 1-11 (1994).

29. J B. Yang, Y. M. Wang, D. L. Xu, K. S. Chin. The evidential reasoning approach for MADM under both probabilistic and fuzzy uncertainties. European Journal of Operational Research, 171: 309-343 (2006).

30. M. Zhou, X. B. Liu, J. B. Yang, et al. Group evidential reasoning approach for MADA under fuzziness and uncertainties. International Journal of Computational Intelligence Systems,6 (3): 423-441 (2013).

31. L. Q. Jin, Y. Xu, X. Fang. A rule base and its inference method using evidential reasoning. The 11th International FLINS Conference on Decision Making and Soft Computing (FLINS2014), Joao Pessoa, Brazil, August 17-20: 330-335 (2014).

32. J. Ma, Z. P. Fan, L. H. Huang. A subjective and goal integrated approach to determine attribute weights. European Journal of Operational Research, 112: 397404 (1999).

33. Z. P. Fan, X. Zhang, F. D. Chen, Y. Liu. Multiple attribute decision making considering aspiration-levels: A method based on prospect theory. Computers and Industrial Engineering, 65: 341-350 (2013).

34. E. H. Shortliffe. MYCIN: Computer-Based Medical Consultations. New York: Elsevier Press (1976).

35. D. Meng. Fuzzy aggregation analysis method based on interval value. Journal of Liaoning Normal University (Natural Science Edition), 26(2): 113-116 (2003). (in Chinese)

36. G. Deschrijver, E. E. Kerre. On the relationship between some extensions of fuzzy set theory. Fuzzy Sets 
and Systems, 133(2): 227-235 (2003).

37. T. Y. Chen, C. Y. Tsao. The interval-valued fuzzy TOPSIS method and experimental analysis. Fuzzy Sets and Systems, 159(11): 1410-1428 (2008).

38. N. G. Mankiw, X. M. Liang, L. Liang. Principles of Economics (5th Edition), Beijing: Peking University Press (2009).

39. W. T. Xiong. Research on methods for interval multi-criteria decision making and their applications. Huazhong University of Science and Technology (2011). (in Chinese)

40. F. E. Boran, S. Genc, M. Kurt, D. Akay. A multicriteria intuitionistic fuzzy group decision making for supplier selection with TOPSIS method. Expert Systems with Applications, 2009(36): 11363-11368 (2009).

41. K. H. Guo, W. L. Li. An attitudinal-based method for constructing intuitionistic fuzzy information in hybrid MADM under uncertainty. Information Sciences, 208:
28-38 (2012).

42. G. Shafer. A mathematical theory if evidence. Princeton University Press, Princeton (1976).

43. C. Heath, R. P. Larrick, G. Wu. Goals as reference points. Cognitive Psychology, 38: 79-109 (1999).

44. P. P. Wakker, H. Zank. A simple preference foundation of cumulative prospect theory with power utility. European Economic Review, 46: 1253-1271 (2002).

45. D. Prelec. The probability weighting function. Econometrica, 66(3): 497-527 (1998).

46. J. M. Zeng. An experimental test on cumulative prospect theory. Journal of Jinan University (Natural Science), 28(1): 44-47, 65 (2007).

47. P. Li, S. F. Liu, J. J. Zhu. Intuitionistic fuzzy stochastic multi-criteria decision-making methods based on MYCIN certainty factor and prospect theory. Systems Engineering-Theory and Practice, 33(6): 1510-1515 (2013). (in Chinese) 